\title{
Sağlık Eğitimi Alan Üniversite Öğrencilerine Verilen El Hijyeni Eğitimi Etkinliği
}

\author{
Hand Hygiene Training Activity Given To University Students \\ Receiving Health Education \\ Gülsüm Kaya ${ }^{1}$, Şeyma Trabzon ${ }^{2}$, Songül Doğanay ${ }^{3}$, Ertuğrul Güçlï ${ }^{4}$, \\ Oğuz karabay ${ }^{4}$, Selma Altındiş ${ }^{5}$ \\ ${ }^{1}$ SB Sakarya Eğitim Araștırma Hastanesi, Enfeksiyon Kontrol Komitesi, Sakarya \\ ${ }^{2}$ SAU Sağlik Hizmetleri MYO, Sakarya \\ ${ }^{3}$ SAU Tip Fakültesi, Fizyoloji AD. Sakarya \\ ${ }^{4}$ SAU Tip Fakültesi, Enfeksiyon Hastalikları AD. Sakarya \\ ${ }^{5}$ SAU İşletme Fakültesi, Sağlık Yönetimi AD Sakarya \\ ORCİD
}

Gülsüm Kaya https://orcid.org/0000-0003-2517-5512

Şeyma Trabzon https://orcid.org/0000-0001-9030-7804

Songül Doğanay https://orcid.org/0000-0002-1730-1331

Ertuğrul Güçlï https://orcid.org/0000-0003-2860-2831

Oğuz Karabay https://orcid.org/0000-0003-1415-1685

Selma Altındiş https://orcid.org/0000-0003-2805-5516

Yazışma Adresi / Correspondence:

Gülsüm KAYA, MSc

SB Sakarya Eğitim Araştırma Hastanesi Enfeksiyon Kontrol Komitesi Sakarya

Tel: +905370289575 E-mail: gulsum_5441@hotmail.com

Geliș Tarihi / Received : 20-11-2019 Kabul Tarihi / Accepted : 01-12-2019

Yayın Tarihi / Online Published: 27-12-2019

Kaya G., Trabzon Ş., Doğanay S., Güçlï E., Karabay O., Altındiş S., Sağlık Eğitimi Alan Üniversite Öğrencilerine Verilen El Hijyeni Eğitimi Etkinliği, J Biotechnol and Strategic Health Res. 2019;3(2):219-224 DOİ:10.34084/bshr.649305

Öz

Amaç El hijyeni, sağlık bakımıyla ilişkili enfeksiyonların (SBİE) önlenmesinde en etkili, en kolay ve en ucuz yöntemdir. Bu çalışmada amaç; Sağlık Hizmetleri Meslek Yüksekokulu’nda (SHMYO) öğrenim gören üniversite öğrencilerine verilen el hijyeni eğitiminin etkinliğini değerlendirmektir.

Gereçve Calısma, gerekli izinler sonrasında, Nisan 2017’de Sakarya Üniversitesi SHMYO’da yapıldı. Eğitimler, enfeksiyon kontrol hemsiresi tarafindan verildi. Görüsme Eğitim Yöntemler öncesi (EÖ) ve eğitim sonrası (ES) öğrencilerden görüșme formunu doldurmaları istendi. Görüșme formu sosyodemografik bilgileri içeren dokuz soru, el yıkama alışkanlığı bilgilerini içeren iki soru ve el hijyeni bilgi düzeyini ölçmeye yönelik oluşturulan on soru olmak üzere toplam 21 sorudan oluşturuldu. Her soruya 10 puan verildi, testten alınabilecek maksimum puan 100'dü. Elde edilen veriler SPSS 21 programında değerlendirildi, $\mathrm{p}<0.05$ anlamlı kabul edildi.

Bulgular Çalıșmaya 103 öğrenci katıldı. Öğrencilerin 24’ü erkek ve 79’u kadındı. Öğrencilerin 85’ $17-20$ yaș arasında ve $18^{\prime}$ i $>21$ yaș ve üzeriydi. Öğrencilerin 43’si tıbbi dökümantasyon ve sekrerterlik, 37’si ilk ve acil yardım, 15’i yaşlı bakımı, 5’i tıbbi laboratuvar ve 3’ü çocuk gelișimi bölümü öğrencisiydi. El yıkama alıșkanlıkları değerlendirildiğinde; öğrencilerin \%70,8’i sık sık el yıkadığını, \%17,4’ü kirli temas sonrası ellerini yıkadığını, \%9,7’si her tuvalet sonrası ellerini yıkadığını ve \%2'si el yıkamadığııı belirtti. EÖ el hijyeni bilgi düzeyi ortancası 70,0 [50,0-80,0] iken ES el hijyeni bilgi düzeyi ortancası 80,0 [65,0-90,0] olarak hesaplandı (p=0.018).

Sonuç Eğitimle beraber öğrencilerin el hijyeni bilgi düzeyi arttı. Öğrencilere düzenli olarak verilecek olan teorik ve uygulamalı eğitimler sağlık personeli adaylarının uyumunu artıracağı düșünüldü.

Anahtar El Hijyeni, El Ylkama, Bilgi, Eğitim, Sağlık Teknikeri Öğrencileri

Kelimeler

Abstract

Objective Hand hygiene is the most effective, easiest and cheapest method in the prevention of nosocomial infections. In this study; the aim of this study is to evaluate the effectiveness of hand hygiene education given to university students studying at Vocational Health High School.

Materials and The study was carried out in Sakarya University Vocational Health High School in April 2017 after the necessary permissions. Educations were given by infection control nurse. Before and Methods after the training (BT-AT); the students were asked to complete the interview form. The interview form consisted of 21 questions: nine questions including sociodemographic information, two questions including hand washing habits and ten questions for measuring hand hygiene knowledge level. Each question is 10 points and the maximum score is 100 . The data were analyzed in SPSS 21 program and $p<0.05$ was considered significant.

Results In total, 103 students participated in the study. Of these, 24 of them were male and 79 were female. 85 of the students were between the ages of $17-20$ and 18 were $>21$ years and older. 43 of the students were medical documentation and secretarial, 37 were first and emergency aid, 15 were aged care, 5 were medical laboratory and 3 were child development department students. When hand washing habits are evaluated; $70.8 \%$ of the students wash their hands frequently, $17.4 \%$ wash their hands after dirty contact, $9.7 \%$ wash their hands after each sink and $2 \%$ said they did not wash their hands. The median level of hand hygiene knowledge level was 70.0 [50.0-80.0] whereas the median level of knowledge of AT hand hygiene was 80.0 [65.0-90.0] ( $p=0.018)$.

Conclusion The knowledge of hand hygiene increased with the education. The theoretical and practical trainings that will be given regularly to all students will increase the harmony among the health personnel candidates.

Keywords Hand Hygiene, Hand Washing, Knowledge, Education, Health Technician Students. 


\section{GIIRIŞ}

El hijyeni, sağlık bakımıyla ilişkili enfeksiyonların (SBİE) önlenmesinde en önemli ve en kolay ancak uyumun da az olduğu bir uygulamadır. El hijyeni olarak da adlandırılan el yıkama evde, işyerinde, hastanelerde her türlü enfeksiyon hastalığını önlemenin en etkili ve ucuz yolları arasindadır ${ }^{1}$. El hijyeni özellikle ishal ve solunum yolu hastalıklarının yayılmasını azaltmaktadır. Hastadan hastaya mikroorganizmaların yayılımı el hijyeni ile en aza indirilebilir². SBİE dışında, genel halk sağlığının korunması ve geliştirilmesi açısından da el yıkama son derece önemlidir ${ }^{3}$.

Son çalışmalar geliştirilmiş el hijyeni uygulamalarının SBİE ve aynı zamanda çoklu ilaç direnci (ÇİD) gösteren organizma bulaşının azaltılmasında en fazla etkiye sahip olduğunu göstermiştir ${ }^{4}$.

Tüm dünyada SBİE’nin insidansı ortalama \% 7-10 civarındadır ve bu enfeksiyonların tedavi maliyeti oldukça yüksektir. Hastane içerisinde yüksek virulans ve çoklu ilaç direnci gösteren mikroorganizmaların hastalar arasında taşınması ve yayılmasında \% 20-40'ında kaynak, sağlık çalışanlarının kirli elleridir. Bu sorunun en az yarısı el hijyeni gibi basit bir işlemle engellenebilir ${ }^{5}$. El hijyeninde temel hedef çapraz kontaminasyonun önlenmesidir. Bunun için uygun ürünle uygun sürede yapılacak uygulama ile el antisepsisinin sağlanmasının yanı sıra gerekli durumlarda eldiven kullanımı önem taşır. El hijyeni için son derece kapsamlı ve kanıt dereceleri ile ifade edilen CDC (Centers for Disease Control and Prevention) önerileri yol göstericidir. Bu kılavuzlar rehberliğinde sağlık personeli eğitimine önem verilmiştir ${ }^{6}$.

Hastane tabanlı araştırmalar, el hijyeni önerilerine uyulmamasının, SBİE ve ÇİD mikroorganizmaların yayılması ile ilişkili olduğunu ve salgınlara büyük oranda katkıda bulunduğunu göstermiştir. Çalışmalar ayrıca, SBİE prevalansının, el hijyeni önlemleri arttıkça azaldığını göstermiştir ${ }^{7}$. Ne kadar pahalı ve sıkı önlemler alınırsa alınsın el hijyenine uyum arttırılmadığı sürece para ve emek boşa gidecektir. Dolayısıyla SBİE’nin kontrolünün olmazsa olmazı el hijyenine uyumdur.

Hastalara birebir hizmet veren sağlık personeli hastanelerde önemli bir yer tutmaktadır. Bu çalışmada amaç, sağlık hizmetleri meslek yüksekokulu (SHMYO) öğrencilerine verilen el hijyeni eğitiminin etkinliğini değerlendirmektir.

\section{Yöntem}

\section{Yer ve Zaman}

Çalıșma, 27 Nisan 2017'de Sakarya Üniversitesi Sağlık Hizmetleri MYO’da öğrenim gören öğrencilerle yapıldı. Çalışmaya başlamadan önce gerekli kurum izinleri alındı.

\section{Evren ve örneklem}

Araştırmanın evrenini Sakarya Üniversitesi SHMYO'da öğrenim gören öğrenciler oluşturdu. Çalışmaya SHMYO’da öğrenim gören ilk ve acil yardım teknikerliği, tıbbi laboratuvar, yaşlı bakımı, tıbbi dokümantasyon ve sekreterlik ve çocuk gelişimi bölümlerinde öğrenim gören 103 öğrenci katıldı. Ders uygulaması amacıyla okul dışında olan öğrenciler çalışma kapsamı dışına alındı.

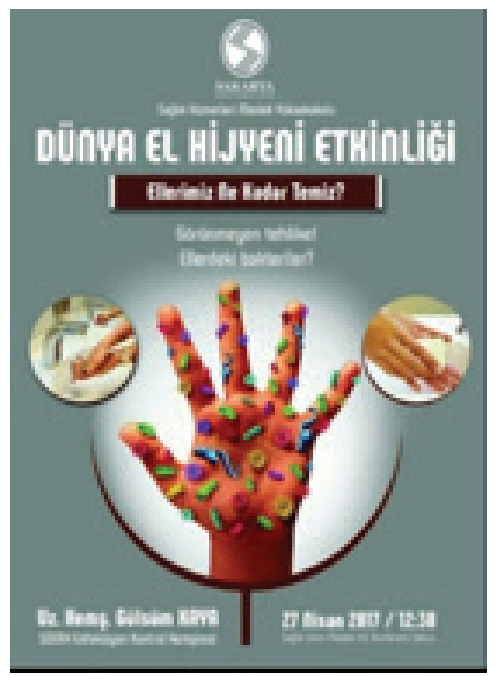

Şekil-1: 5 Mayıs Dünya El hijyeni Günü Etkinliği

\section{Verilerin toplanması ve el hijyeni eğitimi}

5 Mayıs Dünya El Hijyeni Etkinliği kapsamında farkındalık oluşturmak amacıyla Sakarya Üniversitesi SHMYO el 
hijyeni etkinliği gerçekleştirildi (Şekil-1). El Hijyeni eğitimi bir oturum olarak enfeksiyon kontrol hemşiresi tarafından verildi. El hijyeni eğitimi, SBİE önlemede el hijyeninin önemi, el hijyeni sağlama yöntemleri, hijyenik el yıkama, beş endikasyon kuralına göre el hijyeni, antisepsisi ile alkollü el antiseptiği kullanımında dikkat edilmesi uygulamalar ve alınması gereken güvenlik önlemleri ve eldiven kullanımında el hijyeni konu başlıklarını içermekteydi. Eğitime katılan öğrencilere çalışma hakkında bilgi verilerek ön test uygulandı. Eğitimin sonunda son test uygulanarak çalışma sonlandırıldı.

\section{Veri toplama aracı}

Araştırmacı tarafından literatür taranarak oluşturulan görüşme formu, sosyodemoğrafik bilgileri içeren 9 soru, el yıkama alışkanlığı bilgilerini içeren 2 soru ve el hijyeni ile ilgili bilgi düzeyini ölçmeye yönelik oluşturulan 10 soru olmak üzere 21 sorudan oluşmaktaydı. Çalışmaya katılmay1 kabul eden öğrencilerden eğitim öncesi (EÖ) ve eğitim sonrası (ES) görüşme formunu doldurmaları istendi.

\section{Verilerin değerlendirilmesi}

Her soru 10 puan olup testten alınabilecek maksimum puan 100'dü. EÖ ve ES’de öğrencilerden görüşme formu doldurulması istendi. Araştırmadan elde edilen veriler bilgisayar ortamında SPSS 21.0 programında analiz edildi. Elde edilen verilerin normal dağılıma uyup uymadığı Kolmogorow-Smirnov testi ile değerlendirildi. Verilerin istatistiki değerlendirilmesinde; ortalama, standart sapma, frekans ortanca, çeyreklikler arası genişlik, Wilcoxon İşaretli Sıra Testi, Mc Nemar Testi kullanılmıştır. Sonuçlar \% 95'lik güven aralığında, anlamlılık p<0.05 düzeyinde değerlendirilmiştir.

\section{Bulgular}

El hijyeni eğitimine 103 öğrenci katılmış olup, öğencilerin $79(\% 76,6)$ 'u kadın, 85 (\%82,5)'i 17-20 yaş arasında, 70 $(\% 67,9)$ 'i $1 . s ı n ı f$ öğrencisi ve $75(\% 72,8)$ 'i genel lise mezunuydu. Sosyodemografik verilere ilişkin ayrıntılı bilgiler Tablo-1'de verildi.

\begin{tabular}{|c|c|}
\hline Sosyodemografik veriler & n \% \\
\hline \multicolumn{2}{|l|}{ Cinsiyet } \\
\hline Kadın & $79(76,6)$ \\
\hline Erkek & $24 \quad(23,3)$ \\
\hline \multicolumn{2}{|l|}{ Yaş } \\
\hline $17-20$ yaş & $85 \quad(82,5)$ \\
\hline 21 ve üstü yaşı & $18(17,4)$ \\
\hline \multicolumn{2}{|l|}{ Mezun olunan lise } \\
\hline Sağllk Meslek Lisesi & $28(27,1)$ \\
\hline Genel lise ve diğer & $75(72,8)$ \\
\hline \multicolumn{2}{|l|}{ Şuan öğrenim gördüğüi eğitim programı } \\
\hline İlk ve acil yardım programı & $37(35,9)$ \\
\hline Tibbi dökümantasyon ve sekreterlik & $43(41,7)$ \\
\hline Yaşlı bakımı programı & $15(14,5)$ \\
\hline Tibbi laboratuvar teknikleri programı & $5(4,8)$ \\
\hline Çocuk gelişimi programı & $3(2,9)$ \\
\hline \multicolumn{2}{|l|}{ Şuan öğrenim gördüğüi sınıf } \\
\hline 1.sinif & $70(67,9)$ \\
\hline 2.sinif & $33(32,0)$ \\
\hline \multicolumn{2}{|l|}{ Ailenin yaşadığı yer } \\
\hline Köy-kasaba & $21 \quad(20,3)$ \\
\hline İlçe & $40(38,8)$ \\
\hline İl & $20(19,4)$ \\
\hline Büyükşehir & $22(21,3)$ \\
\hline \multicolumn{2}{|l|}{ Ailenin aylık geliri } \\
\hline$<1000 \mathrm{tl}$ & $12(11,6)$ \\
\hline $1000-3000 \mathrm{tl}$ & $56(54,3)$ \\
\hline $3000-5000 \mathrm{tl}$ & $31(30,0)$ \\
\hline $5000-10000 \mathrm{tl}$ & $4(3,8)$ \\
\hline \multicolumn{2}{|l|}{ Anne eğitim durumu } \\
\hline Okuryazar değil & $3(2,9)$ \\
\hline İlköğretim & $60(58,2)$ \\
\hline Ortaöğretim & $30(29,1)$ \\
\hline Yüksekokul & $10(9,7)$ \\
\hline \multicolumn{2}{|l|}{ Baba eğitim durumu } \\
\hline Okuryazar değil & $1(0,9)$ \\
\hline İlköğretim & $47 \quad(45,6)$ \\
\hline Ortaöğretim & $41 \quad(39,8)$ \\
\hline Yüksekokul & $14(13,5)$ \\
\hline
\end{tabular}

Öğrencilerin el yıkama alışkanlıkları değerlendirildiğinde; öğrencilerin 73 (\%70,8)'ü sık sık el yıkadığını, 28 (\%27,1)'i kirli temas sonrası ellerini yıkadığını ve 2 (\%2)'si elleri- 
ni yıkamadığını belirtti (Şekil-2). Öğrencilerin tamamı (n:103) el hijyeni sağlarken sabun kullanmaktaydı.

Öğrencilerin el yıkama alışkanlıkları (n)

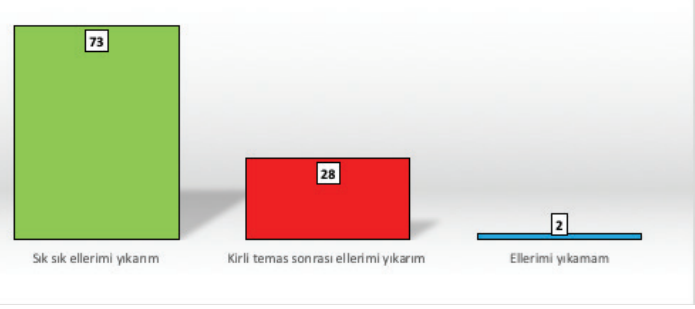

Şekil-2: Öğrencilerin el yıkama alışkanlıkları (n).

Öğrencilerin el hijyeni eğitimi öncesi ve sonrası el hijyeniyle ilgili sorulara verdikleri cevaplar Şekil-3'de gösterilmiştir. EÖ ve ES’de el hijyeni bilgi düzeyleri değerlendirildiğinde; EÖ el hijyeni bilgi düzeyi ortancası 70,0 [50,0-80,0], ES el hijyeni bilgi düzeyi ortancası 80,0 [65,090,0] idi ve EÖ ve ES bilgi düzeyleri arasında anlamlı fark $\operatorname{vard}_{1}(\mathrm{p}=0.018)$. Yaş, cinsiyet, bölüm ve diğer bilgilere göre el hijyeni EÖ ve ES bilgi düzeyleri Tablo-2'de gösterildi.

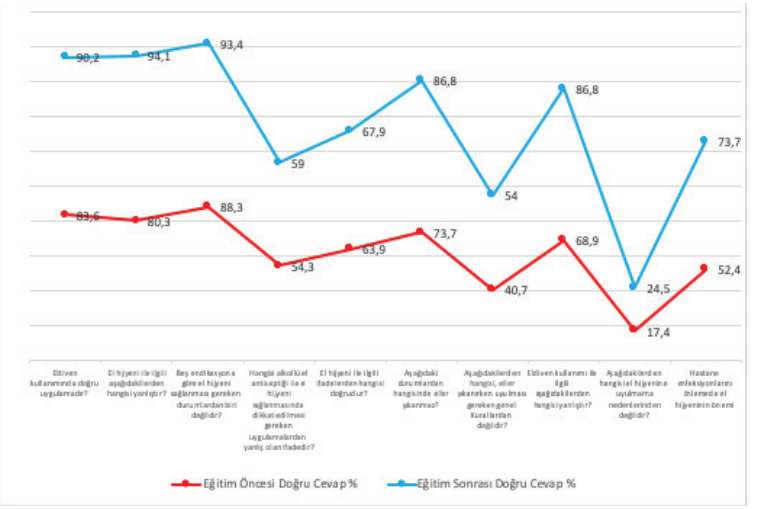

Şekil 3: Öğrencilerin el hijyeni eğitimi öncesi ve sonrası sorulara verdikleri doğru cevaplar (\%).

\begin{tabular}{|c|c|c|c|c|}
\hline & & $\begin{array}{l}\text { Eğitim Öncesi } \\
\text { Bilgi Düzeyi } \\
\text { (n:103) }\end{array}$ & $\begin{array}{c}\text { Eğitim Sonrası } \\
\text { Bilgi Düzeyi } \\
\text { (n:103) }\end{array}$ & $\underset{\text { değeri }}{\mathrm{p}}$ \\
\hline \multirow{2}{*}{ Yaş } & 17-20 Yaş & $70,0[50,0-80,0]$ & $80,0[62,5-90,0]$ & 0.024 \\
\hline & >21 Yaş? & $70,0[50,0-80,0]$ & $80,0[62,5-90,0]$ & 0.414 \\
\hline \multirow{2}{*}{ Cinsiyet } & Erkek & $60,0[32,5-70,0]$ & $80,0[75,0-85,0]$ & 0.010 \\
\hline & Kadın & $70,0[50,0-80,0]$ & $70,0[60,0-90,0]$ & 0.215 \\
\hline \multirow{2}{*}{$\begin{array}{l}\text { Mezun } \\
\text { Olunan } \\
\text { Lise }\end{array}$} & $\begin{array}{c}\text { Sağlik } \\
\text { Meslek Lise- } \\
\text { si Mezunu }\end{array}$ & $70,0[52,5-80,0]$ & $75,0[60,0-90,0]$ & 0.531 \\
\hline & $\begin{array}{l}\text { Diğer Lise } \\
\text { Mezunu }\end{array}$ & $70,0[50,0-80,0]$ & $80,0[70,0-80,0]$ & 0.021 \\
\hline \multirow{5}{*}{$\begin{array}{l}\text { Öğrenim } \\
\text { gördüğü } \\
\text { program }\end{array}$} & $\begin{array}{l}\text { İlk ve acil } \\
\text { yardım } \\
\text { programı }\end{array}$ & $70,0[60,0-80,0]$ & $80,0[60,0-90,0]$ & 0.593 \\
\hline & $\begin{array}{l}\text { Tibbi } \\
\text { döküman- } \\
\text { tasyon ve } \\
\text { sekreterlik }\end{array}$ & $60,0[50,0-70,0]$ & $80,0[70,0-87,5]$ & 0.001 \\
\hline & $\begin{array}{c}\text { Yaşlı bakımı } \\
\text { programı }\end{array}$ & $60,0[60,0-60,0]$ & $80,0[70,0-80,0]$ & 0,001 \\
\hline & $\begin{array}{c}\text { Tibbi } \\
\text { laboratuvar } \\
\text { teknikleri } \\
\text { programı }\end{array}$ & $70,0[50,0-75,0]$ & $80,0[80,0-80,0]$ & 0.157 \\
\hline & $\begin{array}{l}\text { Çocuk } \\
\text { gelişimi } \\
\text { programı }\end{array}$ & $50,0[50,0-50,0]$ & $70,0[70,0-90,0]$ & 0.027 \\
\hline \multirow{2}{*}{$\begin{array}{l}\text { Şuan } \\
\text { öğrenim } \\
\text { gördüğü } \\
\text { sinıf }\end{array}$} & $\begin{array}{c}\text { 1.Sınıf } \\
\text { Öğrencisi }\end{array}$ & $60,0[50,0-72,5]$ & $80,0[70,0-90,0]$ & 0.001 \\
\hline & $\begin{array}{l}\text { 2.Sinıf } \\
\text { Öğrencisi }\end{array}$ & $70,0[70,0-80,0]$ & $70,0[37,5-80,0]$ & 0.267 \\
\hline \multirow{4}{*}{$\begin{array}{l}\text { Ailenin } \\
\text { yaşadığ } 1 \text { yer }\end{array}$} & Köy-kasaba & $70,0[60,0-80,9]$ & $80,0[62,5-80,0]$ & 0.366 \\
\hline & İlçe & $70,0[52,5-80,0]$ & $70,0[62,5-80,0]$ & 0.127 \\
\hline & İl & $60,0[50,0-80,0]$ & $80,0[60,0-90,0]$ & 0.248 \\
\hline & Büyükșehir & $65,0[50,0-80,0]$ & $80,0[67,5-92,5]$ & 0.157 \\
\hline
\end{tabular}

\section{Tartışma}

El hijyeni, SBİE’nin önlenmesinde etkinliği kanıtlanmış standart önlemlerin başında gelir. SBİE etkenlerinin hastalar arasında çapraz kontaminasyonu, çoğunlukla sağlık çalışanlarının elleri aracılığı ile olmaktadır. Bu sayede hastane ortamında virülansı yüksek ve ÇİD gösteren mikroorganizmalar kolaylıkla yayılmakta ve yüksek oranlarda HE'ye neden olmaktadır. El yıkamadaki amaç, ellerdeki gözle görülür kiri uzaklaştırmanın yanı sıra geçici floranın tamamını uzaklaştırmak, kalıcı floranın da sayıca azalmasını sağlamaktır7. Sağlık çalışanlarında ellerin yıkanması 
ya da dezenfeksiyonu geçici flora ile bakteriyel kontaminasyonu engelleyerek, gelişmesi olası enfeksiyonların önüne geçecektir9. Literatürde bu temel bilgileri destekleyen çalışmalar bulunmasına rağmen, sağlık çalışanlarının el hijyeni uygulamalarına uyumu yeterli düzeyde değildir10. DSÖ’nün yürüttüğü bir araştırmada Kosta Rika, İtalya, Mali, Pakistan ve Suudi Arabistan'da 43 hastanede doktorların \% 40'ının, hemşirelerin \% 29'unun, bütün sağlık çalışanlarının ise ortalama \% 49'unun el hijyenine dikkat etmediğini ortaya koymuştur. Program çerçevesinde verilen eğitim sonrasında ise sağlık personelinin el hijyenine dikkat etme oranının \% 51'den 67'ye yükseldiği belirlenmiştir ${ }^{1}$.

Çalışmamızda öğrencilerin EÖ el hijyeni bilgi düzeyi ortancası 70,0; ES el hijyeni bilgi düzeyi ortancası 80,0 olarak saptandı ve EÖ ve ES bilgi düzeyleri arasında istatistiksel olarak anlamlı fark bulundu $(\mathrm{p}<0.018)$. Gözlenen bu farkın eğitim sonu beceri puanı lehine olduğu ve yapılan eğitimin öğrencilerin bilgi düzeyini olumlu yönde geliştirdiğini göstermektedir. Sağlık çalışanı adaylarının el hijyeni ile ilgili bilgi, davranış ve tutumların değerlendirildiği başka bir çalışmada katılımcıların \%50,8'i ellerini sık sık yıkadığını belirtmişlerdir ${ }^{4}$. Çopur Çiçek ve arkadaşları tarafından tıp fakültesi öğrencilerine yönelik düzenlenen el hijyeni eğitim programının etkinliğinin değerlendirildiği çalışmada, katılımcıların \%60'ı el hijyeninin kendileri için yeni bir konu olduğunu ifade etmişlerdir ${ }^{3}$.

Çalışmamızın sonuçları cinsiyete göre değerlendirildiğinde; kadın cinsiyette EÖ ve ES’de anlamlı fark olmazken $(p=0.215)$ erkek cinsiyette EÖ ve ES'de arasında anlamlı fark bulunmuştur ( $\mathrm{p}=0.010)$. Turan ve ark.13'ın yapmış olduğu çalışmada, erkek öğrencilerin el hijyeni bilgi düzeyi puan ortalaması $65,96 \pm 15,62$ ve kadın öğrencilerin el hijyeni bilgi düzeyi puan ortalamasını 71,66 $\pm 13,87$ olarak saptanmıştı ve cinsiyete göre el hijyeni düzeyi bilgi pua$\mathrm{n} ı$ arasında anlamlı fark olduğu bildirilmişti $(\mathrm{p}=0,000)$. Kalıncı (2006), yapmış olduğu çalışmada, el hijyeni davranış puanı ortalamasını erkeklerde $(55,6 \pm 7,8)$ kadınlarda
$(52,2 \pm 8,4)$ göre daha yüksek olarak saptamıştı.14 Şimşek ve ark.15'nın yapmış oldukları çalışmada ise, toplam hijyen puanının kızlarda erkeklere göre daha yüksek olduğu belirtilmiştir. Bu çalışmada toplam hijyen puanının kızlarda erkeklere göre daha yüksek olması, kızlarda toplumsal cinsiyet rollerine bağlı olarak ortaya çıkmış davranış biçimlerinin kişisel alışkanlıklara yansımasının bir sonucu olarak değerlendirilmiş ve erkek öğrencilerin hijyen yetersizlikleri neden ile ortaya çıkacak hastalıklar için risk grubu olarak nitelendirilmesine yol açabileceği öngörülmüştür. Çalışmamızda erkek öğrencilerin verilen eğitimi daha dikkatli dinlediği ve buna bağlı ES'de anlamlı farkın olduğu düşünülmüştür.

Mezun olunan lise türüne göre EÖ ve ES puan ortancaları değerlendirildiğinde; ES'de diğer lise mezunlarında anlamlı bir fark varken ( $\mathrm{p}=0.021)$ sağlık meslek lisesi (SML) mezunu öğrencilerde anlamlı bir fark bulunmamıştır $(\mathrm{p}=0.531)$. Şimsek ve ark. ${ }^{15}$ 'nın yapmış olduğu çalışmada, öğrencilerin öğrenim gördükleri lise türüne göre toplam hijyen puanı ortalamaları değerlendirilmiştir. Çalışmada genel lise eğitimi veren özel lise öğrencilerinin puan ortalaması 18,15, endüstri meslek lisesi öğrencilerinin puan ortalaması 15,46 ve SML öğrencilerinin ise puan ortalaması 16,89 idi ve öğrenim görülen lise türüne göre hijyen puanı ortalamaları arasında anlamlı fark olduğu saptanmıştır $(\mathrm{p}=0.001)$. Çalışmamızda SML mezunu öğrenciler lisede almış oldukları eğitimden dolayı kendilerini daha güvende hissettikleri için el hijyeni eğitimine fazla önem vermemiş olabilir. Düz lise mezunu öğrenciler bu konuda eğitim almadıkları için eğitimi daha dikkatli dinlemiş ve buna bağlı anlamlı bir farkın olduğu düşünülmüştür.

Çalışmamızda birinci sınıf öğrencilerde EÖ ve ES’de puan ortancaları arasında anlamlı bir fark varken $(\mathrm{p}=0.001)$; ikinci sınıf öğrencilerde anlamlı bir fark yoktu ( $\mathrm{p}=0.267)$. İkinci sınıf öğrencileri birinci sınıftayken sağlık ve hijyen eğitimi aldıkları için eğitim düzeyi aynı kalmıştır. Birinci sınıf öğrencileri ise el hijyeni eğitimini daha dikkatli dinlemiş ve buna bağlı bilgi düzeyinin arttığı düşünülmüştür. 
Tüm sağlık çalışanlarının rutin olarak yapması gereken bir işlem olmasına rağmen, bu konuda yapılan tüm çalışmalarda, sağlık personelinin el yıkama sıklı̆̆ının olması gerekenin altında olduğu gözlenmiştir11. Ancak son zamanlarda yapılan teşvik programları ile oranlarda artış olduğu görülse de bu yeterli değildir. Ülkemizde bir üniversite hastanesinde yapılan, asistan doktor ve hemşirelerin katıldığı çalışmada günlük el yıkama sayıları hemşirelerde ortalama $34,5 \pm 24,5$, asistan doktorlarda ise $16,5 \pm 10,5$ olarak daha düşük bulunmuştur. Sosyal el yıkamada ideal olarak kabul edilen süreyi (10-30 sn) hemşireler \% 51 asistanlar ise $\% 48$ oranında doğru olarak yanıtlamışlardır ve aradaki fark anlamlı bulunmamıştır. Ellerin yıkandıktan sonra kurulanması gerektiğini hemşireler \% 83 asistan doktorlar ise \% 67 oranında doğru olarak yanıtlamışlardır. El yıkama sıklığını azaltan sebepleri hemşireler iş yükünün fazlalığı \%58,7, ellerin zarar görmesi \%22,7, lavabo yetersizliği $\% 12$, el yıkanan ortama ve malzemeye güvensizlik $\% 5,3$ olarak yanıtlamışlardır

Çalışmamızda, el hijyeni önemine ilişkin tüm seçenekler potansiyel sağlık yararlarını göstermekte olup literatürlerle uyumludur. Ellerdeki gözle görünür kirlerin giderilmesinde sabun ve su ile el yıkama halen altın standarttır. Bizim çalışmamızda olduğu gibi yapılan diğer çalışmalarda $\mathrm{da}^{4}$ katılımcıların tamamı el hijyeni sağlarken sabun kullandıklarını ifade etmişlerdir. Farklı ülkelerde su ve sabun kullanım oranları farklılık göstermektedir ${ }^{12}$.

SBİE önlenmesi ve kontrolünde sorumluluğu olan sağlık eğitimi alan üniversite öğrencilerinin el hijyeni uygulamalarına ilişkin bilgi düzeyleri eğitim sonrası anlamlı derecede yükseldiği görülmüştür ( $\mathrm{p}=0.018$ ). El hijyeni hastane enfeksiyonlarının önlenmesinde en basit en kolay ve en etkili yöntemdir. Enfeksiyon zincirinin kırılabilmesi, HE’nin önlenmesi ancak bu konuda yeterli teorik ve teknik bilgiye sahip sağlık çalışanlarının farkındalığı ile mümkündür. Sağlık eğitimi alan öğrencilerin hijyen konusundaki farkındalıklarının arttırılması ve bu sürecin el hijyeniyle birlikte, temizlik, sterilizasyon, dezenfeksiyon ve antisepsi de dahil olmak üzere çok yönlü bileşenlerle ele alınabilir. Sonuç olarak bahsedilen tüm bu çalışmalardan ve kendi gözlemlerimizden el hijyenine yönelik eğitim ve uygulamaların sağlık çalışanı adaylarına zorunlu ders olarak verilmesi, en azından enfeksiyon kontrol önlemlerine yönelik ortak bir müfredatın oluşturulması gerektiğini düşünmekteyiz. Eğitim çalışmaları devamlı olmalı, kurumsal şartlara uygun öneriler içermelidir. Eğitimi kolaylaştırıcı, bireyler arası uygulama farklılıklarını en aza indirecek, uyumu artıracak çok yönlü stratejiler geliştirilmelidir.
1. Demirdal T, Uyar S, Demirtürk N. Bir üniversite hastanesinde çalş̦anlarda el yıkama uygulamalarının ve bilgi düzeylerinin değerlendirmesi. The Med J of Kocatepe. 2007; 8(3): 39-43.

2. Weber DJ, Rutala WA, Miller MB, et al. Role of hospital surfaces in the transmission of emerging health care-associated pathogens: norovirus, Clostridium difficile, and Acinetobacter species. American journal of infection control. 2010; 38(5): 25-33.

3. Çiçek ÇA, Atasoy A, Ertürk A. Tip fakültesi öğrencilerine yönelik düzenlenen el hijyeni eğitim programının etkinliğinin değerlendirilmesi. Ankem Derg. 2013; 27(4): 184-195.

4. Türkmen L, Bakır B. Sağllk Teknikeri Adaylarının El Hijyeni (Rutin/El Yıkama) ile İlgili Bilgi, Davranıșve Tutumların Değerlendirilmesi. Gümüş̧hane Üniversitesi Sağlık Bilimleri Dergisi. 2017; 6(3): 122-127.

5. Günaydın $M$, Hastane Enfeksiyonları ve El Hijyeni http://www.das.org.tr/dosya/mg/24seminer.pdf Erișim Tarihi: 20.11.2019

6. Toraman AR, Battal F, Caskurlu H, ve ark. Yoğunun bakım ünitesinde sağllk personelinin el yıkama alışkanlikları. Yeni Tip Dergisi. 2009; 26(2): 85.

7. Arda B, Şenol Ș, Taşbakan MI, ve ark. Ege Üniversitesi Tip Fakültesi yoğun bakım ünitelerinde el temizlĭgi kurallarına uyumun değerlendirilmesi. Yoğun Bakım Dergisi. 2005; 5(3): 182-186.

8. Esen S. Hand hygiene and antiseptics. Sterilization and Disinfection Congress Book. 2003; (2-4 October/ Ankara) http://www.das.org.tr/kitaplar/kitap2003/09.htm Erişsim Tarihi: 26.11.2019
9. Ogeer-Gyles JS, Mathews KA, Boerlin P. Nosocomial infections and antimicrobial resistance in critical care medicine. Journal of Veterinary Emergency and Critical Care. 2006; 16(1): $1-18$.

10. Carey AJ, Saiman L, Polin RA. Hospital-acquired infections in the NICU: epidemiology for the new millennium. Clinics in perinatology. 2008; 35(1): 223-249.

11. Bischoff WE, Reynolds TM, Sessler CN. Handwashing compliance by health care workers: the impact of introducing an accessible, alcohol-based hand antiseptic. Archives of internal medicine. 2000; 160(7): 1017-1021.

12. Togan T, Işılk B, Turan H, ve ark. Aksaray il merkezinde sağlı meslek lisesi öğrencilerinin el hijyeni ve iş kazaları ile ilgili bilgi, tutum ve davranışları. Sağllk Akademisyenleri Dergisi, 2015; 2(1): 8-15.

13. Turan BG, Mankan T, Polat HT. Hemșirelik öğrencilerinin el hijyenine ilișkin bilgi düzeyleri. Gümüşhane Üniversitesi Sağllk Bilimleri Dergisi, 2017; 6(3): 65-70

14. Kalıncı N. Zonguldak İl Merkezi İlköğretim 5.Sinıf Öğrencilerinin El Hijyenine Yönelik Davranışlarının Belirlenmesi. Yüksek Lisans Tezi, Karaelmas Üniversitesi, Zonguldak. 2006.

15. Șimșek Ç, Piyal B, Tüzün H, Çakmak D. Ankara İl Merkezindeki Bazı Lise Öğrencilerinde Kişisel Hijyen Davranışları. TAF Prev Med Bull, 2010;9:433-40 